\title{
CONSTANTINO DE LA FUENTE (1502-1560), DE PREDICADOR ACLAMADO A HEREJE OLVIDADO
}

\author{
POR \\ FRANCES LUTTIKHUIZEN ${ }^{1}$ \\ Universidad de Barcelona
}

\begin{abstract}
RESUMEN
Se hace un repaso de la vida del célebre predicador: su etapa en la Universidad de Alcalá; su amistad con el dr. Egidio; su etapa como magistral de la catedral de Sevilla; su viaje por Europa como predicador en el séquito del príncipe Felipe; sus publicaciones; su biblioteca; su detención por la Inquisición; su ingreso en la cárcel de Triana; su muerte; y la anulación de su memoria. El artículo concluye con una valoración de la relevancia de la obra.
\end{abstract}

PALABRAS CLAVE: Alcalá; Sevilla; Toledo; Évora; Inquisición; limpieza de sangre; auto de fe; literatura clandestina; nicodemismo.

\section{CONSTANTINO DE LA FUENTE (1502-1560), FROM CELEBRATED PREACHER TO FORGOTTEN HERETIC}

\begin{abstract}
We survey the life of the celebrated preacher: his time at the University of Alcalá; his friendship with dr. Egidio; his position as canon of the Cathedral of Seville; his journey through Europe as a preacher in the retinue of crown-prince Philip; his publications; his library; his arrest by the Inquisition; his entry into the prison at Triana; his death; the suppressing of his memory; and the relevance of his work.
\end{abstract}

KEY WORDS: Alcala; Toledo; Seville; Evora; Inquisition; «Cleanliness of blood»; "Auto de fe»; Clandestine literatura; nicodemism.

Cómo CITAR ESTE ARTículo / CITATION: Luttikhuizen, F. 2018. «Constantino de la Fuente (1502-1560), de predicador aclamado a hereje olvidado». Hispania Sacra 70, 141: 29-38. https://doi.org/10.3989/hs.2018.003

\author{
Recibido/Received 08-05-2017 \\ Aceptado/Accepted $\quad$ 08-06-2017
}

Constantino de la Fuente nació en 1502 en San Clemente, provincia de Cuenca. ${ }^{2}$ En el siglo XIV, el pueblo había pasado a formar parte del marquesado de Villena, y en 1445, Juan Pacheco, I marqués de Villena, uno de los hombres más poderosos en la corte de Castilla bajo el reinado de Enrique IV, lo elevó a Villa. En la Guerra de Sucesión que mantuvo Isabel la Católica contra su sobrina Juana la Beltraneja (1476-1479) -entre cuyos seguidores se encontraba Don Diego López Pacheco, II marqués de Villena y duque de Escalona- el pueblo de San Clemente decidió apoyar a

1 francesluttikhuizen@gmail.com / ORCID iD: http://orcid.org/00000002-9887-5184

2 Algunos autores le llaman Constantino Ponce de la Fuente. Esto no es correcto, «Ponce» no formaba parte de su nombre originalmente. Véase Boeglin 2013: 223-230.
Isabel y se reveló contra el poder del marqués. Aunque el duque de Escalona perdió el control de la mayoría de sus pueblos, no se puede desvincular el nombre de Diego López Pacheco de la zona de Cuenca, pues tanto los Mendoza de Guadalajara, como los Pacheco de Escalona, continuaron enriqueciéndose gracias a sus rebaños que pastoreaban en los campos de los alrededores de Cuenca. ${ }^{3}$

La llegada a España del humanismo, y sobre todo de las obras de Erasmo en la segunda década de siglo XVI, impactó de una manera especial en dos familias nobles de la zona: la de Diego Hurtado de Mendoza de Guadalajara y la de Diego López de Pacheco de Escalona. La llamada de Erasmo a un cristianismo purificado encontró una audiencia dispuesta en

\footnotetext{
3 Nalle 1992: 4.
} 
el fermento intelectual y espiritual de la época. La agitación creada por las reformas del Cardenal Cisneros en las filas "observantes» de la orden franciscana, y en ciertos sectores de la sociedad, se convirtió en una nueva espiritualidad entre los humanistas que gravitaban alrededor de Diego Hurtado de Mendoza en Guadalajara. La enseñanza de una religión interior libre de ceremonias externas innecesarias, que preconizaba la vuelta a las fuentes originales del cristianismo, produjo un movimiento laico autóctono o lo que Bernard McGinn define como "teología vernácula», una teología del pueblo en lengua vulgar que no encajaba ni en los parámetros clásicos de teología escolástica ni en los de la teología monástica. ${ }^{4}$ Dos jóvenes de la zona de Cuenca - Constantino de la Fuente y Juan de Valdés - se sentirían atraídos por esta nueva teología y cada uno, a su manera.

Existen lagunas en la biografía de Constantino. El nombre «de la Fuente» no figura entre las familias dominantes de San Clemente. La única mención que he encontrado referente a un posible familiar data de 1570 cuando un tal «Licenciado de la Fuente, abogado de la villa, de edad de 45 años» declara que era tradición y lo más provechoso para el bien común e interés de la república que todas las tiendas de la villa estuviesen ubicadas en la plaza mayor. ${ }^{5}$ ¿Sería este Licenciado de la Fuente hermano o sobrino de Constantino? ¿Buscaba la familia «de la Fuente» reconocimiento social dándoles carreras universitarias a sus hijos? Por otra parte, desde hacía tiempo, residía en San Clemente una importante población de judíos conversos y el hecho de que Constantino procedía de una familia de conversos podría explicar la ausencia del nombre familiar entre las familias hidalgas. ¿Interrumpió sus planes académicos la guerra de los comuneros? No obstante, a mediados de la década de 1520, Constantino estaba matriculado en la Universidad de Alcalá, una institución que estaba gozando de un gran apogeo erasmista. Uno de sus profesores fue el humanista toledano Lorenzo Balbo de Lillo (Toledo), discípulo a su vez del erasmista Pedro de Lerma. De hecho, el primero escrito literario de Constantino fue unos versos laudatorio latinos en honor de Balbo, que aparece en la traducción de Balbo del libro de Valerio Flaco Argonautica (Alcalá, 1524), que utilizaban como libro de texto. ${ }^{6}$

Durante los primeros años Constantino cursaría las disciplinas relacionadas con la elocuencia: Gramática y Literatura latina, Retórica, Dialéctica y Lógica. No sabemos cuántos años estuvo Constantino en Alcalá, ni si llegó a cursar hebreo, griego o Filosofía allí. En todo caso, no se licenció en Alcalá. Aunque algunos autores relacionan su marcha con las disposiciones de limpieza de sangre que se implantaron en la universidad en el curso académico 15321533, creo que su marcha se produjo antes, tal vez en el otoño de 1527 . Toda la facultad de Alcalá estaba implicada en los debates en Valladolid aquel verano para examinar los escritos de Erasmo. Y todos, con la excepción de Pedro Sánchez Ciruelo, se pronunciaron en favor de Erasmo. Cuando ganaron los anti-erasmianos, algunos profesores tomaron sus precauciones. Pedro de Lerma regresó a Burgos, Mateo Pascual se encaminó a Roma. Constantino, que conocía el furor de la Inquisición al haber visto la quema

\footnotetext{
4 Véase McGinn 2005: vol. III, 113-317.

De la Rosa Ferrer 2017.

Gonzalo Sánchez-Molero 2003: 368.
}

de judaizantes pocos años antes en su San Clemente natal ${ }^{7}$, y al no saber en que acabaría el creciente espíritu antierasmiano, optó por abandonar sus estudios en Alcalá. Eran tiempos de confusión y, aunque es cierto que la Inquisición no llegó a quemar a nadie por erasmista, pues «no fue a Erasmo sino a Lutero a quien vieron los inquisidores en sus conciencias y como reflejado en los rostros de sus víctimas ${ }^{8}$, varios de ellos acabaron con sus huesos en la cárcel.

Existe otra posible causa, aunque remota, de su precipitada salida de Alcalá. ¿Fue expulsado? Durante las oposiciones a las que se presentó Constantino para cubrir la vacante de canónigo magistral en Sevilla años más tarde, uno de sus competidores - Pedro de Zumel- "le sacó a relucir todas las frivolidades de su juventud, a saber, que había contraído matrimonio antes de recibir el sacramento del orden y que no había sido ordenado en regla». ${ }^{9}$ No he encontrado ninguna referencia a una norma que excluía alumnos casados, pero esto no significa que no la hubo. Al cabo de unos años, cuando los inquisidores comenzaron a sospechar de Constantino, se pusieron a investigar su vida pasada. Una carta de la Suprema a los inquisidores en Sevilla, fechada el 19 de mayo de 1558, incluía una copia de una carta enviada a los inquisidores de Granada donde recomendaban indagar acerca del supuesto matrimonio de Constantino. ${ }^{10}$ Un año más tarde, la Suprema envió otra carta a los inquisidores de Granada instándoles a interrogar a una tal María González, que vivía en Málaga, con relación a este asunto. La carta incluía las declaraciones de una monja a María González con relación al matrimonio de Constantino. ${ }^{11}$ Por desgracia, el documento donde constarían los resultados de estas pesquisas se ha perdido.

Es poco probable que Constantino volviera a San Clemente. Si tenemos en cuenta que toda la zona de Palencia, Osma, Segovia, Sigüenza y Cuenca caían bajo la jurisdicción eclesiástica de Toledo, es lógico pensar que buscara otro lugar para continuar sus estudios y para ellos elegiría el colegio-universitario del Maese Rodrigo en Sevilla. ${ }^{12}$ El comentario de Reginaldo González de Montes, el primer biógrafo de Constantino, y a quien llamaremos Montes de aquí adelante, nos da una pista:

Era él el único o, desde luego, uno de los poquísimos que en medio de la común ignorancia sabía las tres lenguas, latín, griego y hebreo, habiéndolas aprendido sin ayuda de maestro tan perfectamente, que podía, incluso él solo, restaurarlas. ${ }^{13}$

Estas palabras corresponden seguramente al hecho de que en el colegio-universidad de Maese Rodrigo no se

Constantino presenciaría la quema de Luis Sánchez de Orihuela en 1517 y de Juana Hernández de Astudillo en 1521 por judaizantes. Véase De la Rosa Ferrer 2015.

8 Nieto 1997: 169.

9 González de Montes 2008: 297. Para una descripción detallada del desarrollo del concurso, véase Ollero Pina 2007: 107-196.

10 AHN, Inquisición, leg. 714, doc. 49-3, en López Muñoz 2011: II, doc. $44,121$.

11 ADC, Inquisición, Miscelánea de Breves, L-224, f. 183r, en López Muñoz 2011: II, doc. 53, 137.

12 Tras la muerte de Maese Rodrigo en 1509, Martín Navarro introduciría algunas modificaciones en las Constituciones sobre los requisitos de admisión de los colegiales y que incluía certificados de limpieza de sangre. A partir de 1545 estas exigencias se hicieron más estrictas.

13 González de Montes 2008: 292. 
impartían lenguas bíblicas, como en Alcalá, sino sólo Artes, Lógica, Filosofía, Teología, Medicina y Derecho Canónico y Civil, y por eso había de ser un autodidacto en estas lenguas. Tanto Constantino como su amigo Juan Gil (dr. Egidio) eran:

Miembros del claustro pleno del Colegio Universidad de Santa María de Jesús de «Maese Rodrigo» de Sevilla, y el dr. Egidio impartía clases de Teología desde 1541, en las aulas de "Maese Rodrigo». ${ }^{14}$

Constantino tendría una gran capacidad oratoria y pronto le vemos predicando en la catedral de Sevilla. En junio de 1533 el cabildo catedralicio le invitó a ser uno de sus predicadores. Compartía el pulpito con el dr. Egidio y con el dr. Hernando Rodrígues. El 18 de mayo de 1539, cuando Sevilla celebró las exequias de la emperatriz Isabel de Portugal, que murió en el parto de su sexto hijo, las predicó Constantino de la Fuente, "que, aun no sospechoso, era aplaudido de insigne orador». ${ }^{15}$ El emperador Carlos $V$ le oyó en esta ocasión y sin duda recordaría su elocuencia pues diez años más tarde le nombró predicador de su hijo Felipe en su viaje por Europa. Juan Cristóbal Calvete de Estrella, que documentó minuciosamente el viaje del príncipe, describe a Constantino como:

Muy gran filósofo y profundo teólogo, y de los más señalados hombres en el púlpito y elocuencia que ha habido de grandes tiempos acá, como lo muestran bien claramente las obras que ha escrito de su ingenio. ${ }^{16}$

Tal era su fama al volver del viaje en 1551 que, tras la muerte del predicador Pedro del Campo, el cabildo de Toledo decidió llamar a Constantino sin necesidad de pasar ni siquiera por una oposición. Para ello:

Mandaron una embajada honorífica para traerlo desde Sevilla. Respondió él, sin pararse mucho a deliberar, que les quedaba enormemente agradecido por haberlo considerado digno de tanto honor y que procuraría demostrar que no pareciera que lo habían puesto en un desagradecido. Pero que los huesos de sus padres y abuelos descansaban en la tumba hacía ya muchos años y que él no quería aceptar nada a causa de lo cual se les turbase en aquel descanso. ${ }^{17}$

Era la época del arzobispo Juan Martínez Silíceo y la estricta implantación de los estatutos de limpieza de sangre. ${ }^{18}$ Los partidarios de dichas leyes estuvieron siempre

\footnotetext{
14 Martínez Ripoll 1987: 59-60.

15 Ortiz de Zúñiga 1677: 496.

16 Calvete de Estrella 1930: I, 15.

17 González de Montes 2008: 293.

18 Montes describe la actuación de Silíceo en Toledo: «Se habían producido entonces acérrimas controversias entre el propio arzobispo Silíceo, por cierto, de piadosa memoria, y el cabildo. Pues el arzobispo, que incluso con calificaciones públicas había marcado a los principales miembros del cabildo por el hecho de presentar ascendencia judía en alguna de sus ramas, les era muy hostil; ellos a su vez, impacientes por tan atroz injuria (pues eran, por otra parte, varones honrados y famosos por sus riquezas), causaban todo el daño que podían al majadero obispo, perturbador de la paz pública, el cual desde el arado y los terrones, y no por virtud ni erudición, más bien por una temeridad de la fortuna ( $\mathrm{s}$ se me permite decirlo así), había ascendido raudo y veloz a la más alta dignidad de toda España, a la que sólo el rey precede. En aquella ocasión no había perdón ni aun para los que estaban sepultados hacía ya cien años, haciendo averiguaciones el malvado arzobispo, y esto bajo pretexto de religión, contra los padres, los abuelos, los tatarabuelos de los canónigos, y citándolos muy malvadamente desde sus sepulcros a dar
}

presentes en sus sermones. Son los «malos consejeros» del salmo primero, que describe en sus seis sermones sobre aquel salmo (Beatus vir, 1546):

Ejercen en todo el linaje humano el más bravo género de crueldad que ninguna bestia fiera es posible que ejecute. Porque ésta solamente quitaría la vida y en eso terminaría su fiereza. Estos quitan la honra, quitan la religión, quitan la verdad, acrecientan con sus escarnios las lágrimas y tristezas de los afligidos; y no perdonan ni a los muertos para que no traten de ellos de la misma forma que de los vivos; resucitan a los unos para lastimar a los otros. ${ }^{19}$

El concepto de limpieza de sangre se remonta a la revuelta anti conversa de Toledo de 1449 encabezada por Pedro Sarmiento. Ya en 1480, el Colegio de San Clemente en Bolonia excluyó a «aquellos que habían huido de Sevilla por no ser christianos viejos». Aunque otros colegios mayores también adoptaron estatutos discriminatorios, como el de Santa Cruz de Valladolid (1488) o el de San Ildefonso de Alcalá (1516), pocas sedes episcopales adoptaron estatutos de limpieza de sangre, con la excepción de Toledo. Sin embargo, la barrera de la limpieza de sangre existía. Los que tenían que acceder a determinados cargos debían demostrar que entre sus antecesores no había habido nadie condenado por la Inquisición o que era judío o musulmán. $\mathrm{Si}$ las pruebas genealógicas que presentaba no eran consideradas suficientes, se nombraba una comisión que visitaba las localidades donde podía obtener información y tomar declaraciones juradas a testigos acerca de los ascendientes del pretendiente. Fue esta práctica la que motivó el rechazo de la canonjía de Cuenca también.

Antes de ser convocado por el emperador a ser predicador de su hijo en su viaje de estado por Europa, Constantino había publicado una serie de libros: Suma de doctrina cristiana (Sevilla, 1543); Exposición del primer Salmo de David, cuyo principio es Beatus vir (Sevilla, 1546); Catecismo cristiano, para instruir a los niños (Sevilla, 1547); Confesión de un pecador delante de Jesucristo, redentor y juez de los hombres (Sevilla, 1547); Doctrina cristiana (Sevilla, 1548). ${ }^{20}$ Esta última obra, la más extensa, ha sido también la más ignorada. Doctrina cristiana no es un catecismo, como sostiene José Ramón Guerrero. $^{21}$ Lo que pretendía Constantino con esta obra era presentar un cuerpo de teología sistemática, siguiendo como pauta los tópicos catequéticos; la obra va dirigida a los clérigos. La temática se desarrolla de una manera muy similar a los tratados teológicos de la Reforma. El primer capítulo versa sobre «el conocimiento que debe tener el hombre para con Dios y para consigo mismo». El segundo capítulo amplía la temática al hablar «del conocimiento de Dios y del hombre según la obra de la creación». Seguidamente se hace referencia a la narrativa bíblica sobre el origen del pecado y la promesa de salvación. ¿Tuvo Constantino como modelo algún tratado protestante?

cuenta de sus linajes. Constantino, aprovechando la ocasión de haber sido él llamado, censuraba en pocas palabras con aquel su laconismo tan conciso estas no menos impías que necias confrontaciones». González de Montes 2008: 294.

19 De la Fuente 2008: 168.

20 Para una lista completa de ediciones, véase Luttikhuizen 2017: 455-456.

21 Guerrero 1969. 
Durante su viaje por Europa en el séquito del príncipe heredero Felipe, Constantino tuvo contacto con personas relevantes. Una de ellas fue el predicador luterano de Biberach, Jacobo Schöpper. Según Eduard Boehmer, fue durante unas conversaciones que Agustín de Cazalla tuvo con Schöpper durante la Cuaresma de 1547 donde su dominio de las Sagradas Escrituras le convenció y se convirtió. ${ }^{22}$ ¿Fue Cazalla quien animó a Constantino a procurar un encuentro con Schöpper? No sabemos en qué consistía el encuentro, pero es interesante notar que diez años más tarde fray Luis de Granada publicó en Lisboa, Treinta y dos sermones ${ }^{23}$, una traducción-adaptación hecha por fray Juan de la Cruz de la obra de Jacobo Schöpper Institutionis christianae (Colonia, $1555)^{24}$, una ampliación de su anterior Catechismus brevis (Amberes, 1554). Por prudencia fray Luis de Granada optó por no incluir el nombre del autor de la obra. Según María Dolores Mira Gómez de Mercado, el catecismo de Schöpper «llegó a manos de fray Luis, probablemente través de Joannes [Blavio] de Agripina Colonia, editor de Guía de pecadores, que había montado una innovadora tipografía en Lisboa». ${ }^{25}$ Yo soy de la opinión, y en ello coincido con María I. Resina Rodrígues $^{26}$, de que Constantino de la Fuente tenía algo que ver en esto. En fin, el vínculo Schöpper-Constantino-Luis de Granada necesita ser estudiado más a fondo.

Otra personalidad que Constantino conoció durante su viaje fue el diplomático Gaspar von Nidbruck, el «protestante encubierto con una influencia vital en las cortes de los Habsburgo». ${ }^{27}$ Se conocieron en julio de 1550 en Augsburgo. Al saber que el gran predicador español Constantino de la Fuente estaría en Augsburgo, Nidbruck pidió a Francisco de Enzinas que concertara la entrevista. La amistad entre Nidbruck y Enzinas se remontaba a sus días de estudiantes en Wittenberg bajo Philip Melanchthon. En su carta a Enzinas, Nidbruck dijo:

No es necesario mencionar el tema de la religión, pero le puedes decir que tenga total libertad de comunicarme todo lo que me quiera decir, pues soy una persona de confianza y amigo de hombres de fe y de piedad. Si quieres consultar con él sobre tus propios asuntos, sería mejor hacerlo cuando yo esté en Augsburgo, pues yo podré averiguar con facilidad su postura en cuanto a la pura doctrina evangélica, y sus sentimientos hacia ti, así como la opinión de los demás acerca de ti.

Después de la entrevista, Nidbruck volvió a escribir a Enzinas:

El venerable Dr. Constantino me recibió con gran amabilidad, y, con su sabiduría y erudición, no tengo ninguna duda de que podrá, con tus consejos, promover lo que yo propongo. Lo ha prometido y no desconfío de su buena voluntad. ${ }^{28}$

¿Qué proponía Nidbruck? Sospechamos que el proyecto estaba relacionado con el envío de libros a España. En el otoño de 1550, llegó a Sevilla un gran baúl de libros «luteranos» desde Bruselas. Los libros fueron confiscados.

\footnotetext{
22 Boehmer 2007: II, 19.

23 De la Cruz 1558.

24 Véase Martín Ramos 2005 y Mira Gómez de Mercado 2012.

25 Mira Gómez de Mercado 2012: 199.

26 Resina Rodrigues 1988: 829.

7 Kess 2008: 136.

28 Luttikhuizen 2017: 200.
}

La Suprema sospechaba de Gaspar Zapata, «criado de don Fadrique Enríquez, hermano del marqués de Tarifa, que reside en la corte de su majestad». La carta continúa:

Debe ser preguntado el dicho Gaspar Zapata si entregó a Antonio de Guzmán, un arca de libros luteranos al tiempo que el dicho Antonio de Guzmán partió de Bruselas, los cuales se han tomado por los inquisidores de Sevilla; y que se declare a quién enviaba los dichos libros y si los enviaba en su nombre o en nombre de otro, y quién le escribió o dijo que los enviase y de quién los compró y lo demás que cerca d'ello pasó; y qué es lo que dijo a Antonio de Guzmán al tiempo que se le entregó los dichos libros; y lo que después le escribió que hiciese d'ellos antes que se embarcase, haciéndole sobre todas las otras preguntas que parecerá convenir para saber la verdad cerca de lo susodicho. E habida esta información, cerrada y sellada y en manera que haga fe, se envíe al reverendísimo Inquisidor General o al Consejo de la General Inquisición de estos reinos de España a buen recaudo. ${ }^{29}$

La insistencia en el secretismo nos hace pensar que el destinatario de estos libros era Constantino. Resulta difícil imaginar que Constantino pudiesen crear una biblioteca de cientos de libros "protestantes» sin la ayuda ajena de alguien bien introducido en el tema. Al desempeñar un cargo tan importante en la corte de Maximiliano II, Nidbruck podría fácilmente utilizar el correo diplomático para enviar libros a Sevilla sin que nadie sospechara nada. La otra vía era la clandestina, la que utilizó Juan Pérez de Pineda con Julián Hernández como mensajero entre Alemania y Sevilla.

El príncipe Felipe volvió a Valladolid en el verano de 1551 y, concluidas sus obligaciones oficiales, Constantino volvería a Sevilla. Tanto fue su prestigio como orador que incluso el cardenal-infante D. Henrique de Portugal, arzobispo de Évora, requirió sus servicios como predicador en varias ocasiones. Para ello, Constantino pudo haberse quedado en Portugal una larga temporada, como sugiere Michel Boeglin. ${ }^{30}$ Esto explicaría que una de sus obras - Confesión de un pecador penitente delante de Jesucristo-, impresa en Sevilla en 1547, fuese reeditada en Évora en 1554 por Andrés de Burgos, un impresor granadino trabajando en Sevilla, que fue invitado por el cardenal-infante D. Henrique a establecerse en Évora. El opúsculo de Constantino fue publicado junto con «Dos meditaciones para antes y después de la Sagrada Comunión», de Fray Luis de Granada. ${ }^{31}$ El interés en Portugal por obras españolas que luego acabarían en el Índice de libros prohibidos sirvió de pista siglos más tarde en la búsqueda de obras prohibidas perdidas. Por ejemplo, en 1843 el erudito español Luis de Usoz y Río encontró un ejemplar de Suma de Doctrina (1551) de Constantino en Lisboa ${ }^{32}$ y en 1925 el historiador francés Marcel Bataillon descubrió una copia del Diálogo de doctrina christiana de Juan de Valdés en el Real Monasterio de San Vicente de Forca, cerca de Lisboa.

A la vuelta a Sevilla en 1551 Constantino se encontró con la desagradable sorpresa de saber que había encarcelado a

29 AHN, Inquisición, lib. 574, f. 216r, en López Muñoz 2011: II, doc. $12,52$.

30 Boeglin 2013: 233.

31 Véase Alonso del Campo 2005: 237.

32 Usoz y Río luego incorporaría esta obra en su colección Reformistas Antiguos Españoles. Véase Luttikhuizen 2017: 378-394. Últimamente se han reeditado más obras de Constantino. Véase Luttikhuizen 2016: 418-419. 
su íntimo amigo. En la primavera de 1550, los inquisidores habían llamado al dr. Egidio ante el tribunal para responder a alegaciones presentadas sobre elementos de doctrina luterana en sus sermones. El resultado fue prisión preventiva durante dos años que culminó con un debate público en la catedral entre el dominico Domingo de Soto y Egidio y una sentencia de tres años de prisión - dos de los cuales ya había cumplido- y a diez años de inhabilitación del cargo. ${ }^{33}$ ¿Qué conclusiones sacaría Constantino de estos acontecimientos?

Poco tiempo estuvo Constantino en Sevilla, pues al cabo de tres años fue requerido de nuevo para acompañar al príncipe Felipe a Inglaterra para su casamiento con su pariente la reina Mary I de Inglaterra, que se celebró el 25 de julio de 1554. No obstante, aprovechando estos tres años, Constantino sometió un nuevo manuscrito - titulado: Espejo del estado del hombre en esta presente vida- al Consejo para su aprobación, así como permiso para reimprimir su Beatus vir y su Catecismo. ${ }^{34}$ Una lectura detenida de la correspondencia que sigue entre Sevilla y Madrid da a entender que la Suprema había enviado esos libros a Alcalá para su calificación y luego los había vuelto a enviar a Sevilla, juntamente con el manuscrito, sin pronunciarse sobre este último, lo que sorprendió a los inquisidores de Sevilla. El 28 de septiembre de 1553, la Suprema les escribió de nuevo en relación al manuscrito:

Reverendos señores: Luego que nos enviástes el libro de mano que ha hecho el doctor Constantino que se intitula Espejo del estado del hombre en esta presente vida, proveímos cómo lo viesen los doctores de Alcalá, que habían dado el primer parecer sobre el libro de los seis sermones, y el licenciado Carlos, que allí habíamos enviado a otro negocio, para que lo cualificasen y viesen si en él se respondía y satisfacía a todas las cosas y proposiciones que estaban votadas en los libros de los seis sermones. Y visto por ellos, ha parecido de os tornar, señores, a enviar ambos libros y el parecer de los de Alcalá, para que le hagáis enmendar en el libro de El espejo del estado del hombre los lugares donde llama la fe de los pecadores falsa, y que en el otro libro de los seis sermones se pueda hacer lo que ha parecido a los dichos doctores de Alcalá. ${ }^{35}$

Seguía siendo el predicador más aclamado. Incluso el catedrático de retórica Alfonso García Matamoros en su famoso apología de la nación española De adserenda Hispanorum eruditione (Alcalá, 1553) le alaba y le dedica «el juicio más sincero posible a sus dotes oratorias y poéticas». ${ }^{36}$ Uno de los primeros cometidos de Constantino al volver a Sevilla en la primavera de 1555 fue el de predicar los viernes, miércoles y lunes de Cuaresma, alternándose con el dr. Francisco Meléndez y el dr. Gonzalo Millán. ${ }^{37}$ Constantino había estado muy enfermo y se sentía tan débil que le habían de llevar a la catedral en litera. Una vez recuperado, el dr. Alonso de Escobar, rector de la Casa de los Niños de la Doctrina, le pidió a él y al canónigo Hernán Ruiz de Hojeda

\footnotetext{
33 Véase Luttikhuizen 2017: 190-191.
}

34 AHN, Inquisición, lib. 574, f. 374v, en López Muñoz 2011: II, doc. 24, 99.

35 AHN, Inquisición, lib. 574, f. 392r, en López Muñoz 2011: II, doc. 26,101 . El libro no se llegó a imprimir y el manuscrito se ha perdido.

36 Martínez Ripoll 1987: 63. Estas palabras de elogio fueron suprimidas en ediciones posteriores.

37 Ollero Pina 2007: 186. que enseñaran en su escuela. ${ }^{38}$ Según Montes (2008, 297), Constantino «empezó por los libros de Salomón, los Proverbios, el Eclesiastés y el Cantar de los Cantares y, una vez explicados éstos con admirable erudición, se dedicó al libro de Job, en cuya interpretación llegó hasta más allá de la mitad «.. ${ }^{39}$

Mientras tanto, el cabildo de la catedral había decidido ofrecerle a Constantino la «canonjía de oradores» que el dr. Egidio había regentado desde 1537 y había dejado vacante tras su detención y posterior muerte en 1555. En 1531, el dr. Egidio había opositado a la cátedra de Prima de Santo Tomás en Colegio de San Ildefonso de Alcalá, pasando al curso siguiente a leerla en la Universidad de Sigüenza. En Alcalá fue sustituido por el cordobés Pedro Alexandro, quien, a su vez en 1533, sería promovido a la canonjía magistral de Sevilla. Dado que Alexandro acababa de ser nombrado capellán de la hermana del emperador María de Austria, gobernadora de los Países Bajos, no podía aceptar la invitación de Sevilla, invitó a Egidio a ocupar su lugar y el cabildo no tuvo ningún reparo en admitirle sin examen previo, cosa que lamentaron luego.

Las reglas de la casa exigían un examen público previo a la admisión, requisito que habían omitido con el dr. Egidio en 1537, así que se anunció el examen el 15 de febrero de 1556. Siete candidatos se inscribieron. ${ }^{40}$ Los ejercicios orales habían de comenzar hacia finales de abril. Rápidamente todos los opositores, menos el obispo de Málaga, Pedro Zumel, protegido del arzobispo Fernando de Valdés y del provisor de Sevilla el inquisidor Juan de Ovando, se retiraron. Constantino quedó exhausto y el día 11 de mayo, su abogado trajo un certificado, firmado por el dr. Nicolás Monardes, constatando que Constantino estaba demasiado enfermo para continuar, y que redundaría en perjuicio de su vida si lo hiciera. ${ }^{41}$ Podría tratarse de una especie de recaída de su dolencia anterior. Los jueces tomaron en cuenta la situación, y no continuaron los exámenes; al día siguiente proclamaron vencedor a Constantino. Montes describe el evento:

Así pues, se convocó la oposición, tras cuya divulgación a través de las ciudades más célebres de España pronto se presentaron algunos predicadores como los buitres al reclamo de un suculento cadáver; pero, habiéndose retirado del concurso los más sensatos aterrados por la fama y autoridad de Constantino, únicamente perseveraron en el concurso, ávidos de una presa bastante sustanciosa, Majuelo, canónigo de Alcalá de Henares y otro de Málaga. Pero también aquél, atendiendo a mejores razonamientos, se volvió poco después a Alcalá de Henares, perseverando pertinazmente en el concurso el malagueño, ayudado enérgicamente por el favor del arzobispo [Valdés] que odiaba a Constantino. [...] Así pues, el competidor, que de ninguna manera se podía comparar con Constantino ni en erudición ni en autoridad ni, finalmente, en el favor del cabildo, canalizando todos su intentos hacia las excepciones a su persona, le sacó a relucir todas las frivolidades de su juventud, a saber, que había contraído matrimonio antes de recibir el sacramento del orden y que no había sido ordenado en regla, ni había recibido en forma debida los grados de magisterio y doctorado. Desde la otra ala lo asediaba una cohorte de hipócritas, antiguos enemigos, quienes, del

\footnotetext{
38 Ibídem: 179.

39 González de Montes 2008: 297.

40 Ibídem: 151-152.

41 Olmedilla y Puig 1897: 26.
} 
mismo modo que por aquella fracasada promoción se recrudecía la úlcera de su envidia, así también, renovadas todas las antiguas cuestiones de doctrina, lo responsabilizaban de ellas con más gravedad que nunca antes lo hicieran, y esto ante el tribunal inquisitorial, en que con suma autoridad ostentaba la presidencia el arzobispo Valdés, ya su nuevo enemigo. ${ }^{42}$

Como es evidente, Constantino no era bien amado por todos. Había recelos acerca de sus enseñanzas y celos acerca de su fama, pero él continuaba predicando en la catedral y sus sermones tenían un gran impacto. ${ }^{43}$ Sus adversarios vigilaban muy de cerca tanto sus palabras como su conducta. Según Montes, sus tres principales enemigos eran: «Esbarroya, sofista dominico, Pedro Mexía, hombre que se arrogaba ridículamente el título de filósofo sin nada de buenas letras, y Pedro Díaz, el inquisidor». De los tres, el teólogo escolástico Agustín de Esbarroya expresaba mejor los postulados teológicos del bando contrario a las predicaciones de Constantino. ${ }^{44}$ La brecha venía de la época cuando el dr. Egidio fue denunciado como hereje luterano y encarcelado. Acerca de la actitud de Pedro Díaz durante el juicio de Egidio, Juan Antonio Llorente comenta:

El licenciado Corro, inquisidor decano, respetó y defendió su virtud en contraposición de su socio Pedro Díaz, cuyo ánimo estaba exaltado contra el reo; lo cual era tanto mas sensible cuanto este había seguido antes las mismas opiniones aprendidas de boca de Rodrigo de Valer. ${ }^{45}$

Según el historiador Martín de Roa, Pedro Mexía precipitó la detención de Constantino:

Sucedió un día, que acabando de predicar Constantino, Pedro Mexía, hombre por sus buenas letras y escritos conocido, saliendo de la iglesia, dijo: "Vive el Señor que no es esta doctrina buena, ni es esto lo que nos enseñaron nuestros padres». Causó no poco alboroto esta razón, dicha de un hombre tan grave y estimado, y dio atrevimiento para que algunos se resolviesen a manifestar las sospechas que tenían en su pecho de que Constantino era hereje. Comenzaron a fallarle los más amigos, y a dar parte a la Inquisición de lo que pasaba. Llamáronle algunas veces aquellos señores, y los que le veían ir tantas veces y venir del castillo [de San Jorge en Triana] preguntáronle qué le querían. Respondióles: «Queríanme quemar estos señores, sino que me hallan muy verde». ${ }^{46}$

No tardaría en llegar el día en que las acusaciones alcanzaron un alto grado de madurez y la máquina del terror empezó a rodar. La firmeza espiritual de Constantino empezó a debilitarse y el temor a la hoguera hizo mella en su testimonio. En este marco de flaqueza espiritual y de peligro inminente, a principios de 1558 - dos años después de su elección como canónigo magistral-, Constantino tomó la

42 González de Montes 2008: 297.

43 Benito Arias Montano fue un oyente entusiasta de Constantino. Véase Martínez Ripoll 1987: 58.

44 El fraile dominico Agustín de Esbarroya, profesor en el Colegio de Santo Tomás de Sevilla, publicó Purificador de la conciencia en 1550, donde enfatizaba la importancia de las obras y atacaba la enseñanza de «la fe sola». Nieto 1997: 190-191.

45 Llorente 1835: III, 212.

46 Martín de Roa. 1600?. Historia d'esta provincia la Compañía de Jesús de Andaluzía: ms. 331/23, fol. 48v. Biblioteca de la Universidad de Sevilla. sorprendente decisión de solicitar ingreso en la Compañía de Jesús. Este hecho, investigado a fondo por William B. Jones ${ }^{47}$, es de lo más desconcertante. Parece ser que al principio la reacción de los jesuitas sevillanos fue receptiva, pero ante las crecientes pruebas de herejía que se acumulaban en contra de Constantino, optaron por dar largas al asunto, hasta que, finalmente, rechazaron la petición. Jones cree que Constantino fue sincero en su petición. David Estrada Herrero opina que el intento de Constantino por entrar en la Compañía de Jesús ha de enmarcarse, una vez más, en el contexto general del nicodemismo al que se vieron sometidos la mayoría de los evangélicos españoles de aquella época. ${ }^{48}$

Coincidiendo con esto, Juan Pérez de Pineda, un profesor de la Casa de la Doctrina de Sevilla huido a Ginebra, se dedicaba a fomentar la causa evangélica a distancia enviando cartas y libros mediante mensajeros. Las autoridades estaban al tanto de sus actividades, pues el 17 de noviembre de 1557 la Suprema envió una carta a Felipe II, que todavía estaba en Flandes, que decía:

Nos escriben que han traído a [Sevilla] muy gran número de libros que contienen muchas herejías, los cuales se han hallado en poder de personas principales d'aquella çiudad y de fuera d'ella, y que tienen relación que un doctor Juan Pérez, que reside en Francafort, gran amigo del doctor Egidio, que se fue d'aquella çiudad cuando le prendieron, los compuso y envió con un español luterano que está preso; y con los dichos libros venían algunas cartas del doctor para las dichas personas. Proçédese en el examen de aquel hombre y en el negoçio tocante a las personas en cuyo poder están los libros. De lo que subçediere daremos aviso a vuestra majestad.

También nos escriben que tienen aviso que el doctor Juan Pérez ha enviado muchos de los dichos libros a esa corte, y no sabemos a qué personas. A vuestra majestad suplicamos sea servido de mandar proveer que luego se recojan y las personas que los tienen sean castigadas, porque la desvergüença y astuçia d'estos herejes es tan grande que con gran dificultad se puede proveer por los ministros del Santo Ofiçio el remedio que conviene. $E$ importa mucho que en estos negoçios vuestra majestad mande se haga gran demostración, para que estos herejes se refrenen en no cometer semejantes delitos con tanta osadía. ${ }^{49}$

El «español luterano» enviado por Juan Pérez con el cargamento de libros era Julián Hernández («Julianillo»). Su arresto en el verano de 1557 tuvo serias consecuencias para los evangélicos en Sevilla. Algunos de los libros iban destinados a Constantino, pero no le arrestaron. Al contrario, el 22 de octubre, la Suprema mandó a Sevilla un despacho donde se insistía a los inquisidores que procediesen con mucha cautela. Temían que Constantino se les escaparía como lo hicieron los monjes de San Isidoro. No obstante, los inquisidores sabían que debían actuar con rapidez. ${ }^{50}$

47 Jones 1964: 447-473.

48 De la Fuente 2008: 71.

49 AGS, Estado, leg.121, doc. 165, en López Muñoz 2011: II, doc. $35,113$.

50 «... si de su receptoría resultare alguna cosa en que fuere necesario examen, hágase sin que se le dé resultado, sino que responda luego [de inmediato], porque con darle término [tiempo] para responder es darle ocasión para que él comunique con cuantos quisiere para ofuscar el negocio de manera que no se entienda». AHN, Inquisición, lib. 575, f. 57r y ss, en López Muñoz 2011: II, doc. 34, 112. 
Ante la expansión del movimiento evangélico en Sevilla y el rápido incremento de prosélitos, el inquisidor general Fernando de Valdés se sirvió de los plenos poderes que le otorgaba el papa Pablo IV para poner en práctica «un nuevo método de represión basado en el terror del ejemplo». ${ }^{51}$ El día 1 de agosto de 1558, Constantino predicó su último sermón en la catedral de Sevilla. Quince días más tarde, Valdés ordenó su encarcelamiento y empezaron los interrogatorios. Durante los primeros meses, Constantino supo evadir las acusaciones:

Eludiendo fácilmente con sus agudísimas respuestas, según su costumbre, todas sus cavilaciones, no podía ser arrastrado a una confesión abierta de su fe a partir de la cual se le crease peligro, como ellos profundamente deseaban. ${ }^{52}$

La prueba final de su heterodoxia vino de la manera más inesperada. Cuando Julián llegó a Sevilla en 1558 con «mucha cantidad de libros prohibidos y cartas para muchas personas de Sevilla», nadie podría sospechar que los libros destinados a Isabel Martínez de Alvo eran de hecho libros destinados a Constantino de la Fuente. A escondidas de todos, menos de Isabel y su familia, Constantino había reunido una gran biblioteca clandestina que guardaba detrás de una falsa pared en casa de Martínez de Alvo. Cuando los alguaciles fueron a por Isabel, como hicieron con todos los destinatarios de los libros de Julianillo, su hijo Beltrán dio por hecho que le preguntarían por la biblioteca de Constantino. Así pues, cuando los alguaciles volvieron al día siguiente, en búsqueda de unas joyas que ella había escondido, sin más, Beltrán les llevó directamente a los libros de Constantino. Montes describe la escena con detalles propios de un testigo ocular:

Fue detenida exactamente por aquellos mismos días una viuda piadosa y honesta y extraordinariamente opulenta, Isabel Martínez, en cuya casa había escondido Constantino con motivo de las asechanzas de los Inquisidores el ajuar más selecto de sus libros, o sea, aquellos que no se pueden tener en España sin muy inminente peligro. Cuando estaban siendo secuestrados, como es costumbre inquisitorial, los bienes de aquella viuda, su hijo Francisco Beltrán había sustraído de todo el rico ajuar de la madre no sé cuántas arcas llenas de objetos bastante valiosos, no fuera que todas las riquezas fuesen engullidas en aquel abismo insaciable de la Inquisición. Aquello lo denunció algunos días después cierto criado pérfido. En consecuencia, los Inquisidores enviaron a su alguacil Luis Sotelo a buscar aquellos objetos. Tan pronto como él se dirigió a Beltrán, en el momento en que empezó a exponerle con palabras educadas su encargo, Beltrán, olvidándose quizá de las arcas por haber pensado que él había venido por el asunto de los libros de Constantino, adelantándose a sus palabras, le dijo: "Sé, don Luis, qué queréis; y si de buena fe me prometéis que, una vez recibidas las cosas por las que habéis venido, me dejaréis libre, al punto os las mostraré». El alguacil, creyendo que se refería a las arcas (pues ni buscaba los libros de Constantino, ni había oído una palabra sobre ellos) le promete que así lo hará; y al instante Beltrán, introducido aquél en la parte más secreta de la espaciosísima mansión y derribado un delgado tabique de ladrillo, le muestra los tesoros de Constantino, de papel, ciertamente, pero que valían

\footnotetext{
51 Bataillon 1966: 709.

52 González de Montes 2008: 298.
}

más que todos los de oro. El alguacil, estupefacto por tan inesperado suceso, le dice que él ciertamente no ha venido a buscar aquello sino algunas arcas que había sustraído del secuestro de los bienes maternos; y que la palabra dada no le impedía llevarse ante los Inquisidores tanto al propio Beltrán como los libros; y así, finalmente, todos los escritos de Constantino que eran de alguna importancia llegaron a las manos de los Inquisidores desde aquellos escondrijos hasta la luz meridiana, al margen de lo que esperaban él y sus adversarios, lo cuales, por lo demás, habrían comprado con gran cantidad de oro aquel botín. Fue hallado entre otras muchas cosas un libro enorme totalmente escrito de la propia mano de Constantino, en el cual, de una forma abierta y como si sólo escribiera para sí mismo, trataba principalmente de estos capítulos (según relataron los propios Inquisidores en su sentencia hecha pública después en el teatro), a saber: "Del Estado de la Iglesia», "De la verdadera Iglesia y de la Iglesia del Papa», al que llamaba Anticristo, "Del sacramento de la Eucaristía y del invento de la Misa», asunto del que afirmaba que el orbe estaba fascinado por ignorancia de la Sagrada Escritura, "Del Purgatorio», al que llamaba cabeza de lobo e invento de frailes para llenar su vientre, «De las Bulas e Indulgencias papales», "De los méritos de los hombres», «De la Confesión» y, finalmente, de todos los otros capítulos de la religión cristiana. Después de haber sido examinado este libro, interrogado Constantino por los Inquisidores sobre si reconocía su letra, habiendo eludido la respuesta durante muchos días mediante subterfugios rebuscados desde todas partes, reconociendo, al fin, la voluntad de Dios que le había cortado toda ocasión de utilizar ya más pretextos, dijo: «Reconozco mi letra y, por tanto, confieso que yo he escrito todas esas cosas las cuales también manifiesto sinceramente que son verdaderas. Y no tenéis por qué esforzaros más en buscar contra mí otros testimonios; aquí tenéis ya una confesión clara y amplia de mi opinión, actuad en consecuencia y haced de mí lo que mejor os parezca». ${ }^{53}$

El «libro enorme totalmente escrito de la propia mano de Constantino» descrito por Montes no fue destruido inmediatamente. Incluso parece ser que los mismos inquisidores hicieron una copia a petición del Consejo:

Los días pasados se os escribió que holgaríamos de ver los tratados que se hallaron del doctor Constantino, y él los había reconocido antes que falleciese, que si no fuese mucha escritura, nos enviásedes su traslado [copia]. Encargamos os, señores, que nos los enviéis por la orden que mejor os parecerá, y también informad de cómo acabó en lo último el dicho doctor Constantino, y si hizo alguna declaración o muestra de arrepentimiento. ${ }^{54}$

Todos los bienes de Constantino fueron confiscados cuando entró en prisión y todo quedó bien registrado por el provisor Pedro de Morga. ${ }^{55}$ En el informe de Morga consta que Constantino tenía unas casas en Sevilla y que había recibido desde 1548 un salario anual de Felipe II de unos 100.000 maravedís. Las casas no fueron derrocadas. En 1575 fueron ocupadas «por vida» por el ex canónigo Hernán Ruiz de Hoje-

53 Ibídem: 298-299.

54 AHN, Inquisición, leg. 2942, doc. 113, en Schäfer 2014: II, doc. $327,509$.

55 El en caso del dr. Egidio, se habían olvidado de confiscar sus bienes cuando fue detenido, así que lo primero que hicieron, una vez muerto y declarado hereje, fue vender la lápida de su tumba (después de borrar su nombre) por catorce ducados. AHN, Inquisición, leg. 4683 (3), en López Muñoz 2011: II, doc. 158, 324. 
da una vez cumplido con su condena de reclusión en la casa que tenía la Compañía de Jesús en Sevilla. ${ }^{56}$ Sería emocionante para Hojeda poder ocupar las casas de Constantino, pues durante muchos años habían enseñado juntos en la Casa de los Niños de la Doctrina..$^{57}$ Otras de sus posesiones fueron vendidas. Según Morga, «treinta mil maravedís valieron los aparejos y letras de una imprenta que se hallaron en el secuestro de sus bienes». Esto, mas los 367 libros que fueron vendidos en subasta pública en septiembre de 1562, según Morga, cubría adecuadamente los gastos incurridos durante su encarcelamiento, que subieron a 30.672 maravedís. ${ }^{58}$ La venta de la pequeña imprenta y los aparejos alcanzó un buen precio, pero los libros pequeños no, pues, según Morga, «había poco interés en esta clase de libro». Entre los libros grandes que pusieron a la venta había una copia de la Biblia Complutense. La compró fray Lucas de la Sal, quien la vendió luego a fray Martín de Ábrego, quien a su vez la legó al Monasterio de San Agustín de Jerez de la Frontera. Años más tarde, la Suprema solicitó a los inquisidores de Sevilla que la recuperasen. ${ }^{59}$ Si fue posible o no, no hay constancia.

Entre los papeles de Constantino, también había un recibo fechado el 17 de septiembre de 1558, firmado por el impresor humanista Martín Montesdoca (Montes de Oca) por valor de 400 escudos de oro..$^{60} \dot{ }$ Era un avance por parte de Constantino para imprimir El espejo del estado del hombre o la segunda parte de su Doctrina Christina, u otra cosa? A partir de 1554, Montesdoca se había dedicado exclusivamente a imprimir libros religiosos: dos libros del místico franciscano Francisco de Osuna, Luz del alma del dominico fray Felipe de Meneses ${ }^{61}$, y media docena de obras de fray Domingo de Baltanás. Hacia 1557, Montesdoca empezó a tener dificultades económicas. El año siguiente, Constantino le entregó 400 escudos de oro. ${ }^{62}$ ¿Era éste un gesto simplemente de amistad, o un gesto para evitar la ruina de Montesdoca? Sea como fuere, en noviembre de 1559, Montesdoca, viudo y con dos hijos pequeños, vendió su taller en Sevilla y sus posesiones en Utrera y compró pasajes para él, sus dos hijos y su hermana Marina en la nave «Nuestra Señora de la Antigua» y, el día 22 de enero de 1561, zarparon para Honduras. Sin duda, el arresto de Constantino aceleró la marcha de Montesdoca. El informe de Francisco de Naveda, notario de los secuestros, dice: «el dicho Montesdoca quebró y se fue en Indias. Hase escrito allá y enviado recaudos para cobrar. D'él no hay respuesta ni se tiene esperanza de cobrar nada». ${ }^{63}$

56 AHN, Inquisición, leg. 2943, doc. 81, en López Muñoz 2011: II, doc. 131, 280; AHN, Inquisición, leg. 2946, doc. 30, en López Muñoz 2011: II, doc. 234, 426.

57 Ollero Pina 2007: 179.

58 AHN, Inquisición, leg. 4683 (3), en López Muñoz 2011: II, doc. $158,330$.

59 AHN, Inquisición, leg. 2946, en López Muñoz 2011: II, doc. 228, 422.

60 AHN, Inquisición, leg. 4683 (3), en López Muñoz 2011: II, doc. $158,335$.

${ }^{61}$ Cervantes elogia este libro: «Y [don Quijote] pasó adelante a otro cajón, donde vio que estaban corrigiendo un pliego de un libro que se intitulaba Luz del alma; y, en viéndole, dijo: Estos tales libros, aunque hay muchos deste género, son los que se deben imprimir, porque son muchos los pecadores que se usan, y son menester infinitas luces para tantos desalumbrados». (DQ II, 62).

62 Wagner 1982: 26.

63 AHN, Inquisición, leg. 2943, doc. 144 (2), en López Muñoz 2011: II, doc. 163, 342.
El aclamado predicador pasó casi dos años en la cárcel inquisitorial de Triana. Parece ser que su criado Francisco de Mendoza se escaparía, pues le encontramos en la primavera de 1559 en Barcelona a punto de zarpar para Nápoles en compañía de Per Afán de Ribera, que iba como nuevo virrey de Nápoles. Cuando estaban todos a punto de embarcar, el tribunal de Barcelona recibió órdenes del Consejo de detenerle. ${ }^{64}$ Mendoza logró escapar de nuevo y los inquisidores le buscaron por Cuenca -era oriundo de San Clemente, como Constantino- y Málaga, pero inútilmente. ${ }^{65}$ Finalmente, en la primavera de 1564, Mendoza se entregó voluntariamente. Durante su proceso contó que «doña Ana [de Deza] e Isabel Martínez [de Alvo] le escribían y comunicaban por cédulas y cartas con el doctor Constantino, estando preso, por medio de Pedro de la Haya, alcaide difunto». ${ }^{66}$ Mendoza abjuró de levi y fue penitenciado en el auto de fe celebrado del 19 de marzo de 1564. Su sentencia dice:

Francisco de Mendoza, natural de la villa de San Clemente, en el marquesado de Villena, criado que fue del doctor Constantino. Condenado por perturbador e impedidor del Santo Oficio; y traía recaudos y mensajes para los presos, y trataba de sobornar el alcaide de las cárceles; en cuerpo, soga y vela y doscientos azotes por las calles de Sevilla, y recluso en el lugar y por el tiempo que pareciere a los señores inquisidores. ${ }^{67}$

Constantino no fue nunca sometido a tormenta (Montes: 2008, 300) y durante el último año en Triana, un tal fray Fernando del Monasterio de San Isidoro compartía celda con Constantino, asistiéndole en sus enfermedades. Murió a principios de 1560 :

A consecuencia de aquel régimen de vida del todo pésimo $y$, sobre todo, consumido por una tristeza enorme y absolutamente inconsolable al ver que con la devastación tan truculenta de aquella piadosísima Iglesia quedaban aniquilados tantos y tan continuados esfuerzos suyos y de sus piadosos compañeros. Empezó primero a estar levemente enfermo, y después, al no poder soportar el fortísimo ardor del sol en aquellos hornos, estando día y noche desnudo hasta sin camisa, afectado de disentería, a los quince días, en medio de aquel ambiente sórdido, entregó a Cristo su alma feliz. ${ }^{68}$

Una vez muerto, era cuestión de borrar su memoria. Lo primero que hicieron era borrar su nombre del púlpito de mármol situado el Patio de los Naranjos de la catedral, desde donde predicaba. Sus libros fueron puestos inmediatamente en el Índice de libros prohibidos del inquisidor general Fernando de Valdés de 1559. Cuando la expurgación se convirtió en una alternativa a la prohibición definitiva, a

64 AHN, Inquisición, lib. 736, f. 374r, en López Muñoz 2011: II, doc. $59,143$.

65 ADC, Inquisición, Miscelánea de Breves, L-224, f. 183r, en López Muñoz 2011: II, doc. 53, 137. El motivo era para interrogarle sobre si Constantino había estado casado.

66 AHN, Inquisición, leg. 2943, doc. 127-1, en López Muñoz 2011: II, doc. 155, 318. Ana de Deza e Isabel Martínez de Alvo también estaban presas. Ana de Deza sobornaba a los carceleros a menudo para conseguir favores. Véase Luttikhuizen 2017: 271-275.

67 AHN, Inquisición, leg. 2075, doc. 4, en López Muñoz 2011: II, doc. 156, 321)

68 González de Montes 2008: 300. 
partir de $1571^{69}$, borraron su nombre de los libros. Por ejemplo, su nombre fue expurgado de El felicissimo Viaje de Calvete. En el Índice publicado por Sandoval y Rojas (Madrid, 1612, fol. 5), se lee: «que se quite todo lo que es en alabanza de Constantino de la Fuente, autor condenado». Las instrucciones del Índice último de los Libros Prohibidos, editado por Agustín Rubin de Cevallos e impreso en Madrid por Antonio de Sancha en 1790, no cambiaron. Seguían igual de tajantes. En cambio, el historiador sevillano Diego Ortiz de Zúñiga rectificaría el texto de Calvete, pero con las siguientes reservas:

Partió el Príncipe a embarcarse en Rosas, de donde se hizo a la vela a dos de noviembre, acompañándolo muchos grandes, títulos y caballeros [...] y en cuya compañía pasó el Doctor Constantino de la Fuente, aplaudido entonces por gran teólogo, y predicador, condenado después por pervertido hereje, a que siempre su altivez y presunción lo tuvo muy sujeto, pero entonces tan lejos de las sospechas que predicó al Príncipe en Barcelona, el día de Todos Santos, cuyo memorable viaje escribió muy cumplidamente Cristóbal Calvete de Estrella. $^{70}$

En la ciudad de Sevilla se acababa de celebrar el gran auto de fe de septiembre de 1559, así que tuvieron que esperar al próximo auto para relajarle públicamente. Así que, su cadáver fue exhumado y sus huesos fueron llevados al próximo auto junto con una estatua de él vestida de un sambenito pintado con demonios. ${ }^{71}$ Son varios los informes inquisitoriales sobre los penitenciados aquel 22 de diciembre de 1560, unos más extensos que otros. Bajo el título de «Difuntos relajados en estatua por la secta luterana» encontramos:

El doctor Constantino de la Fuente, canónigo que fue de la canonjía magistral de la dicha Santa Iglesia, difunto, natural de San Clemente. Condenada su memoria y fama, y relajada su estatua y huesos por hereje luterano con confiscación de bienes. ${ }^{72}$

La descripción de Montes del impacto de aquella escena resume en pocas palabras la vida de Constantino:

En sustitución del muerto se puso una estatua de paja colocada sobre un púlpito con una mano levantada y con la otra agarrada al púlpito, que representaba en vivo a Constantino con aquel ademán con que habitualmente había predicado. Y no hay duda de que aquella estatua vacía predicó a las almas de muchos igual de eficazmente que como lo había hecho antes en vida aquel a quien por escarnio representaba. ${ }^{73}$

En el contexto de la celebración de los 500 años de la Reforma protestante la vida y el pensamiento de Constantino cobran renovado interés. Si bien los escritos de Lutero tuvieron una temprana distribución en la península, no fue la influencia directa de los escritos del reformador alemán que inició en España el movimiento evangélico de retorno a las fuentes bíblicas del cristianismo. La España del siglo XVI era ya, de hecho, un fermento de inquietudes religiosas. Amplios

69 Véase Luttikhuizen 2017: 364.

70 Ortiz de Zúñiga 1677: 506.

71 AHN, Inquisición, leg. 2075, doc. 2, en López Muñoz 2011: II, doc. 100, 212.

72 BNE, ms. 9175, f. 258r, en López Muñoz 2011: II, doc. 102, 219.

73 González de Montes 2008: 300-301. sectores del pueblo buscaban una más personal comunión con Dios a través de la lectura y meditación de relevantes pasajes de la Escritura. Los escritos de Constantino encierran una constante apelación al mensaje y la autoridad de las Escrituras. En el primer sermón de su Exposición del primer psalmo de David: cuyo principio es "Beatus vir», Constantino utiliza una y otra vez los términos paulinos de «justificación» y «justificar». En el segundo sermón afirma Constantino que, si bien el hombre fue creado a semejanza de Dios, representa más bien «la imagen de su enemigo el Diablo». Con este recurso a la imagen del Diablo pretende enfatizar los resultados la total imposibilidad del hombre para conseguir por sí mismo un retorno al estado original de creación. La moraleja doctrinal de esta comparación es obvia: el hombre no puede de ninguna manera cooperar en la economía de la salvación. La salvación del pecador es fruto de la pura gracia de Dios — una doctrina netamente protestante- También en el tema de la elección como epicentro de la soteriología bíblica el acuerdo de Constantino con los teólogos de la Reforma es total:

El creyente ha de saber que, antes que pudiese hacer bien o mal, lo eligieron y señalaron para que fuese justo $y$, por justo, bienaventurado. No fue esto por sus obras ni por su merecimiento, pues, antes que el pudiese obrar fue elegido... El mismo que lo eligió, es el que lo justifica, el que lo favorece y sustenta, para que conforme a la elección haga obras semejantes a las obras de su unigénito Hijo, pues fue elegido y señalado para que fuese semejante a la imagen de él. ${ }^{74}$

Comparte también Constantino con los reformados la idea zwingliana de una iglesia invisible en el seno de una iglesia visible - la ecclesiola en ecclesia de Lutero-. En su aspecto visible, la Iglesia predica fielmente la Palabra de Dios, administra correctamente los sacramentos y ejerce la disciplina sobre sus miembros. En su aspecto invisible la Iglesia es el cuerpo de los elegidos, la comunidad de los creyentes de todos los tiempos: la Iglesia católica, la Iglesia universal. Dice textualmente:

Hay dos clases de miembros en la Iglesia: unos vivos y otros muertos; unos que tienen fe viva y otros que tienen fe muerta. La Iglesia invisible está formada únicamente por los que tienen verdadera santidad y están unidos a la Cabeza, que es el Hijo de Dios, dador de todos los bienes. ${ }^{75}$

Fueron estas mismas palabras, y otras parecidas, que le dieron fama de gran predicador y que veinte años más tarde le condenaron por hereje luterano. ¡Qué paradoja!

\section{BiBLIOGRAFÍA}

Alonso del Campo, U. 2005. Vida y obra de Fray Luis de Granada. Salamanca: San Esteban.

Bataillon, M. 1966. Erasmo y España: estudios sobre la historia espiritual del siglo XVI. México: Fondo de Cultura Económica.

Boeglin, M. 2013. «Irenismo y herejía a mediados del siglo XVI en Castilla. El caso de Constantino de la Fuente», en I. J. García Pinilla (ed.), Disidencia religiosa en Castilla la Nueva en el siglo XVI: 223249. Ciudad Real: Almud.

Boehmer, E. 2007. Bibliotheca Wiffeniana. [Estrasburgo, 1874-1904]. Pamplona: Analecta Editorial. 3 vols.

\footnotetext{
74 De la Fuente 2008: 168.

75 De la Fuente 2017: X, f. 266r-f. 321v.
} 
Calvete de Estrella, J. C. 1930. El felicissimo viaje del muy alto y muy poderoso principe don Philippe, hijo del emperador don Carlos Quinto Maximo, desde España a sus tierras de la baxa Alemaña. [Amberes: M. Nucio, 1552]. Madrid: Sociedad de Bibliófilos Españoles. 4 tomos.

De la Cruz, J. 1558. Treynta y dos sermones en los quales se declaran los mandamientos de la Ley artículos de Fe y Sacramentos con otras cosas provechosas sacadas de Latín en Romance. Lisboa: Joannes Blauio de Colonia.

De la Fuente, C. 2008. "Exposición del primer Salmo de David», en E. Monjo Bellido (ed.), Obras de los reformadores españoles del siglo XVI: V, 71 y 168. Sevilla: Editorial MAD. [Introducción y notas de David Estrada Herrero].

De la Fuente, C. 2017. «Doctrina Christiana, en que está comprehendida toda la información que pertenece al hombre que quiere servir a Dios. Parte primera» [Sevilla, 1548], en E. Monjo Bellido (ed.), Obras de los reformadores españoles del siglo XVI: X. Terrassa: CLIE. [Introducción y notas de David Estrada Herrero].

De la Rosa Ferrer, I. 2015. «Los Origüela de San Clemente: Astudillos y Piquinotis». Entrada en el blog: Historia del corregimiento de San Clemente. 1 de septiembre. https://historiadelcorregimientodesanclemente.blogspot.com.es/2015/09/los-oroguela-de-san-clemente-astudillos.html [Accedido el 7-4-2017].

De la Rosa Ferrer, I. 2017. «Las tiendas de San Clemente hacia 1570: la ruptura de la moral y sociedad tradicionales». Entrada en el blog: Historia del corregimiento de San Clemente. 2 de abril. https://historiadelcorregimientodesanclemente.blogspot.com.es/search?q= Las+tiendas+de+San+Clemente [Accedido el 7-4-2017].

González de Montes, R. 2008 [1567]. Artes de la Santa Inquisición Española. Sevilla: Editorial MAD. [Traducido del latín por Fco. Ruiz de Pablos].

Gonzalo Sánchez-Molero, J. L. 2003. El erasmismo y la educación de Felipe II (1527-1557). Madrid: Universidad Complutense.

Guerrero, J. R. 1969. Catecismos españoles del siglo XVI. La obra catequética del Dr. Constantino Ponce de la Fuente. Madrid: Instituto Superior de Pastoral.

Jones, W. B. 1964. Constantino Ponce de la Fuente. The Problem of Protestant Influence in Sixteenth-Century Spain. Tesis doctoral inédita. Nashville, Tenn: Universidad de Vanderbuilt.

Kess, A. 2008. Johann Sleidan and the Protestant Vision of History. Aldershot: Ashgate.

Llorente, J. A. 1835. Historia crítica de la inquisición de España. Barcelona: Oliva. 4 vols.
López Muñoz, T. 2011. La Reforma en la Sevilla del siglo XVI. Sevilla: Editorial MAD. 2 vols.

Luttikhuizen, F. 2016. Underground Protestantism in Sixteenth Century Spain. Göttingen: Vandenhoeck \& Ruprecht.

Luttikhuizen, F. 2017. España y la Reforma Protestante (1517-2017). Vigo: Editorial Academia del Hispanismo.

Martín Ramos, N. 2005. Cristo, sacramento de Dios en Fray Luis de Granada. Salamanca: San Esteban.

Martínez Ripoll, A. 1987. "La Universidad de Alcalá y la formación humanista, bíblica y arqueográfica de Benito Arias Montano». Cuadernos de Pensamiento 12: 58-63.

McGinn, B. 2005. The Presence of God: A History of Western Christian Mysticism. New York: Crossroad.

Mira Gómez de Mercado, M. a D. 2012. Actualización, estudio y edición del Diálogo sobre la necesidad de la oración vocal, obras virtuosas y santas ceremonias de fray Juan de la Cruz (1555). Almería: Universidad de Almería.

Nalle, S. T. 1992. God in La Mancha: Religious Reform and the People of Cuenca 1500-1650. Baltimore: Johns Hopkins University Press.

Nieto, J. C. 1997. El Renacimiento y la otra España. Ginebra: Droz.

Olmedilla y Puig, J. 1897. Estudio histórico de la vida y escritos del sabio médico español del siglo XVI, Nicolás Monardes. Madrid: Hernández.

Ollero Pina, A. 2007. «Clérigos, universitarios y herejes. La Universidad de Sevilla y la formación académica del cabildo eclesiástico», en L. E. Rodríguez San Pedro-Bézares y J. L. Polo Rodríguez (eds.), Universidades Hispánicas. Modelos territoriales en la Edad Moderna (I): Santiago, Toledo, Sevilla, Barcelona y Huesca: 107196. Universidad de Salamanca.

Ortiz de Zúñiga, D. 1677. Annales eclesiásticos y seculares de la muy noble y muy leal Ciudad de Sevilla, metropoli de Andalucia: Que contienen sus mas principales memorias desde el año de 1246 en que emprendio conquistarla S. Fernando Tercero de Castilla y Leon hasta el de 1671 en que la Iglesia Católica le concedió el culto y t'tiulo de bienaventurado. Madrid: Garcia Infançon.

Resina Rodrigues, M. I. 1988. Fray Luis de Granada y la literatura de Espiritualidad en Portugal (1554-1632). Madrid: FUE.

Schäfer, E. H. J. 2014. Protestantismo Español e Inquisición en el Siglo XVI. Sevilla: Editorial MAD. 4 vols. [Traducido por Fco. Ruiz de Pablos].

Wagner, K. 1982. Martín de Montesdoca y su prensa: contribución al estudio de la imprenta y de la bibliografía sevillanas del siglo XVI. Sevilla: Universidad de Sevilla. 